\title{
Analisis Kelayakan Usaha Kecil dan Menengah Pengelolaan Dodol Nanas Tulimario Desa Tangkit Baru Muaro Jambi
}

\author{
Bambang Kurniawan \& Ade Andriani \\ Fakultas Ekonomi dan Bisnis Islam UIN Sulthan Thaha Saifuddin Jambi
}

\begin{abstract}
Abstrak: Tulisan ini bertujuan untuk mengetahui ketersediaan bahan penunjang dodol nanas, keuntungan dan prospek perkembangannya di Desa Tangkit Baru Kabupaten Muaro Jambi. Metode penelitian yang digunakan dalam penelitian ini adalah pendekatan deskripktif. Hasil analisis ini disajikan dalam angka dan diinterpretasikan dalam suatu uraian. Temuan penelitian menunjukkan bahwa bahan penunjang dodol nanas di Desa Tangkit Baru seperti gula pasir dan tepung terigu masih tersedia, UKM dodol nanas ini juga menguntungkan. Keuntungan yang diperoleh dalam setahun sebesar Rp173.077.680, dan prospek perkembangannya semakin maju, dengan membuat varian baru seperti dodol nanas crispy dan produk lain yang memperluas pangsa pasar.
\end{abstract}

Kata-kata kunci: Usaha Kecil dan Menengah; Dodol Nanas; Tulimario Tangkit Baru

\section{Pendahuluan}

Buah nanas akan tersedia sepanjang tahun dalam jumlah maupun mutu yang sesuai dengan permintaan konsumen. Ini berarti pula suatu usaha agar tidak terjadi panen buah nanas secara serempak yang mengakibatkan harga buah nanas menjadi rendah. karena harga buah nanas tidak pernah stabil atau menjadi rendah di pasaran hingga sering membuat para petani menjadi bingung dan bahkan buah nanas kebanggaan Tangkit Baru ini tidak laku dijual. Bahkan, sering buah nanas tidak jadi dipanen sipemilik nya karena tingginya biaya operasional dan distribusi dari lahan perkebunan hingga di pasar dan tidak sebanding dengan nilai jualnya yang sangat rendah. Buah nanas yang berukuran kecil banyak kita temui busuk dipinggir jalan Desa Tangkit Baru karena tidak termasuk kriteria permintaan. Maka muncullah strategi dari para petani untuk mengolah buah nanas menjadi bahan produksi yang dapat dijual dengan sistem kemasan. Sehingga jangkauan pemasarannya bisa lebih luas lagi, tidak hanya masyarakat Kota Jambi saja namun luar kota dan tidak hanya menjual buah yang di panen dari kebun, tetapi sudah bisa diekspor baik dengan kemasan dan olahan yang baru keseluruh daerah di Indonesia bahkan hingga keluar negeri.

Untuk pasar luar negeri, kriteria standar mutu buah ditentukan Negara pengimpornya. Maka buah-buahan yang tidak memenuhi standar mutu tersebut dapat dimanfaatkan menjadi dodol. Pengolahan buah-buahan menjadi dodol merupakan salah satu upaya untuk memperpanjang daya simpan buah dan menekan kehilangan pasca panen pada buah-buahan. Pengembangan usaha industri dodol dengan skala usaha kecil menengah memiliki prospek yang cukup baik, mengingat potensi pasarnya sangat mendukung. Selain itu, proses pembuatan 
dodol buah pada dasarnya tidak terlalu sulit dan memiliki nilai ekonomis yang cukup menggiurkan ${ }^{1}$

Pengolahan buah nanas ini bertujuan agar daya tahannya lebih lama dan awet. Selama ini untuk buah nanas segar biasanya hanya bisa bertahan dan dapat disimpan selama kira-kira 1-7 hari saja. Tim ahli industri kecil pengolah buah nanas di Tangkit membuktikan nanas olahannya bisa bertahan sampai delapan bulanan lebih. Berdasarkan pemaparan petani nanas di tangkit bahwa pada saat musim panen raya/panen besar di Tangkit Baru Kab. Muaro Jambi biasanya harga nanas di pasaran akan lebih murah, hingga para petani banyak yang merugi. Karena itulah maka timbul ide untuk mengolah nanas ini agar punya nilai jual dan bisa bertahan dipasaran. Menurut mereka dengan pengelolaan buah nanas menjadi dodol nanas dapat menjawab permasalahan yang dialami selama panen raya dan disadari meningkatkan pendapatan masyarakat ${ }^{2}$ Melalui penelitian oleh Tim Ahli Industri Kecil Pengolah Buah nanas di tangkit, telah ditemukan beberapa produk unggulan yang terbuat dari buah nanas yaitu Dodol nanas, dodol nanas goreng, selai nanas Goreng, selai nanas, sirup nanas dan keripik nanas. Produk unggulan prioritas peringkat pertama adalah dodol nanas dengan jumlah produksi/bulan sebesar 4.000 kotak.

Selain itu terpilihnya dodol nanas sebagai produk unggulan diantara kelima produk unggulan Industri Kecil Pengolah Buah nanas di Tangkit karena dodol memiliki keunggulan seperti dodol nanas merupakan makanan tradisional yang cukup populer di beberapa daerah Indonesia dan memiliki rasa yang khas dan enak. Rasa dan aroma dodol nanas yang dihasilkan akan sama dengan buah aslinya yaitu tergantung pada kualitas nanas yang digunakan Berdasarkan keunggulankeunggulan yang dimiliki dodol nanas tersebut, maka diperlukan suatu analisis untuk mengetahui sejauh mana kemampuan Industri Pengolahan Buah nanas di Tangkit layak dikembangkan dan bagaimana prospek pengembangannya. Produksi nanas di Tangkit Baru mengalami peningkatan setiap tahun, bisa kita lihat pada tabel berikut.

Tabel 1

Jumlah Produksi Nanas

\begin{tabular}{|c|c|c|}
\hline No & Tahun & Jumlah Produksi \\
\hline 1 & 2012 & 124.456 Ton \\
\hline 2 & 2013 & 115.897 Ton \\
\hline 3 & 2014 & 146.480 Ton \\
\hline 4 & 2015 & 167.679 Ton \\
\hline 5 & 2016 & 187.403 Ton \\
\hline
\end{tabular}

Sumber Data: Kantor Desa Tangkit Baru

${ }^{1}$ Suyanti Satuhu dan Sunarmami, Membuat Aneka Dodol buah, (Jakarta: Penebar Swadaya, 2010), hlm.76.

2Dinar Tresnawati, Analisis Pengembangan Agroindustri Dodol Nanas di Kabupaten Subang, (Surakarta: Skripsi, 2010), hlm.15. 
Berdasarkan data pada tabel diatas dapat diketahui bahwa buah nanas di Tangkit Baru Kabupaten Muaro Jambi mengalami penurunan produksi di tahun 2013 dan mengalami peningkatan produksi dari tahun 2014-2016.

Oleh karena itu, tulisan ini akan berfokus mengurai analisis kelayakan Usaha Kecil Menengah (UKM) Pengelolaan Dodol Nanas Tulimario di Tangkit Baru Kabupaten Muaro Jambi.

\section{Ketersediaan Bahan Penunjang Pada Industri Dodol Nanas}

Bahan penunjang yang digunakan dalam proses pengelolahan dodol nanas adalah tepung terigu, dan gula pasir. Berdasarkan hasil wawancara dengan responden diketahui bahwa kebutuhan tepung terigu dan gula pasir untuk dodol nanas dapat diperoleh di pasar yang terletak tidak jauh dari daerah penelitian dan untuk memperlancar ketersediaan pasokan tepung terigu dan gula pasir responden memiliki beberapa pelanggan atau pihak yang diberi kepercayaan memenuhi permintaan tepung terigu, gula pasir dan setiap kali akan berproduksi.

Adapun ketersediaan tepung terigu dan gula Pasir untuk tahun 2017 di Kabupaten Muaro Jambi.

Tabel 2

Ketersediaan Konsumsi Tepung Terigu, Gula Pasir Kabupaten Muaro Jambi dan Kebutuhan Industri UKM Tulimario 2017

\begin{tabular}{|c|l|c|c|c|}
\hline No & \multicolumn{1}{|c|}{$\begin{array}{c}\text { Bahan } \\
\text { Penunjang }\end{array}$} & $\begin{array}{c}\text { Ketersediaan } \\
\text { Kg }\end{array}$ & Konsumsi kg & $\begin{array}{c}\text { Kebutuhan } \\
\text { Industri } \\
\text { Tulimario } \\
\text { Kg }\end{array}$ \\
\hline 1 & $\begin{array}{l}\text { Tepung } \\
\text { Terigu }\end{array}$ & 2.992 .000 & 1.301 .000 & 2.688 \\
\hline 2 & Gula Pasir & 3.539 .000 & 2.949 .000 & 3.888 \\
\hline
\end{tabular}

Dari tabel diatas dapat dilihat bahwa ketersedian bahan penunjang yang digunakan dalam industri pengelolaan dodol nanas di Kabupaten Muaro Jambi mencukupi.

Ketersediaan tepung terigu di kabupaten Muara Jambi sebanyak 2.992.000/kg sedangkan konsumsi tepung terigu sebanyak 1.301.000/kg Untuk industri pengeloaan dodol nanas di tahun 2017 kebutuhan tepung terigu sebanyak $2.688 / \mathrm{kg}$ (Produksi Dodol nanas dilakukan 20 kali dalam sebulan dengan pembagian 8 kali produksi dodol nanas dan 12 kali produksi untuk dodol nanas crispy perbulan, sekali produksi dodol nanas menghabiskan tepung terigu sebanyak $7 \mathrm{~kg} / \mathrm{hari}$, menghabiskan tepung terigu $7 \times 8=56 \mathrm{~kg} / \mathrm{bulan}$, dan menghabiskan tepung terigu $56 \times 12=672 \mathrm{~kg} /$ tahun. Dan untuk dodol nanas crispy menghabiskan tepung terigu sebanyak $14 \mathrm{~kg} /$ hari, mengabiskan tepung terigu $14 \times 12=168$ /bulan dan menghabiskan tepung terigu $168 \times 12=2.016 /$ tahun, total tepung terigu yang dipakai produksi dodol nanas dan dodol nanas crispy dalam setahun adalah $672+2.016=2.688 \mathrm{~kg} /$ tahun $)$. 
Jadi dapat disimpulkan bahwa ketersediaan tepung terigu di daerah penelitiaan tersebut mencukupi kebutuhan tepung terigu untuk industri pengelolaan dodol nanas. Ketersediaan gula pasir di Kabupaten Muaro Jambi sebanyak 3.539.000/kg, konsumsi gula pasir di Kabupaten Muaro Jambi sebanyak $2.949 .000 / \mathrm{kg}$ sedangkan kebutuhan gula pasir untuk industri pengeloaan dodol nanas di tahun 2017 sebanyak 3,888kg/tahun (sekali produksi dodol nanas menghabiskan gula pasir sebanyak $18 \mathrm{~kg} /$ hari, menghabiskan gula pasir 18x8=144 $\mathrm{kg} / \mathrm{bulan}$, dan menghabiskan gula pasir $144 \times 12=1.728 \mathrm{~kg} /$ tahun. Dan untuk dodol nanas crispy menghabiskan gula pasir sebanyak $15 \mathrm{~kg} /$ hari, mengabiskan te $15 \times 12=180$ /bulan dan menghabiskan gula pasir sebanyak $180 \times 12=2.160$ $\mathrm{kg} /$ tahun, total gula pasir yang dipakai produksi dodol nanas dalam setahun adalah $1.728+2.160=3.888 \mathrm{~kg} /$ tahun Jadi dapat disimpulkan bahwa ketersediaan gula pasir di daerah penelitian tersebut mencukupi kebutuhan, kebutuhan gula pasir untuk industri pengeloaan dodol nanas.

\section{Keuntungan Pada Industri Pembuatan Dodol Nanas}

Keuntungan adalah total penerimaan dikurangi biaya produksi dalam satu tahun produksi. Penerimaan adalah nilai rupiah dari total produksi yang dihasilkan dikali dengan harga jual produk. Biaya produksi yang dimaksud adalah semua pengeluaraan dalam pengelolaan dodol nanas. Berikut tabel penerimaan, biaya dan keuntungan responden di daerah penelitian pada tahun 2017.

Tabel 3

Penerimaan, Biaya dan Keuntungan Pada Industri Pembuatan Dodol nanas di Daerah Penelitian Responden Tahun 2017

\begin{tabular}{|c|c|c|c|c|c|}
\hline No & Sampel & $\begin{array}{c}\text { Total } \\
\text { produksi } \\
\text { Dodol }\end{array}$ & $\begin{array}{c}\text { Total } \\
\text { Penerimaan } \\
(\mathrm{Rp} / \mathrm{Thn})\end{array}$ & $\begin{array}{c}\text { Total Biaya } \\
\text { Produksi } \\
\text { (Rp/Thn) }\end{array}$ & $\begin{array}{c}\text { Total } \\
\text { Keuntungan }\end{array}$ \\
\hline 1 & $\begin{array}{l}\text { Dodol } \\
\text { nanas }\end{array}$ & 19.200 & 192.000 .000 & 126.196 .128 & 65.803 .872 \\
\hline 2 & $\begin{array}{l}\text { Dodol } \\
\text { nanas } \\
\text { crispi }\end{array}$ & 28.800 & 288.000 .000 & 180.726 .192 & 107.273 .808 \\
\hline 3 & Total & 48.000 & 480.000 .000 & 306.992 .320 & 173.077 .680 \\
\hline
\end{tabular}

Dari tabel diatas diketahui bahwa dengan asumsi 1 tahun responden aktif bekerja membuat dodol nanas selama 240 hari ( satu kali produksi dilakukan selama satu hari dan dalam satu minggu produksi dilakukan sebanyak lima kali, dan dalam satu bulan produksi dilkukan sebanyak 20 kali, 8 kali produksi dodol nanas dan 12 kali produksi dodol nanas crispy perbulan ) maka diperoleh produksi dodol nanas sebesar $48.000 \mathrm{ktk} /$ thn ( sehari produksi dodol nanas menghasilkan $200 \mathrm{kotak} / \mathrm{hari}, 200 \times 8=1.600 \mathrm{kotak} /$ bulan dan $1.600 \times 12=19.200$ kotak/tahun. Sedangkan dodol nanas crispy menghasilkan 200 kotak/hari, 200x12=2.400 
kotak/bulan dan $2.400 \times 12=28.800$ kotak/tahun, total produksi dodol nanas dan dodol nanas crispy menghasilkan $19.200+28.800=48.000 \mathrm{kotak} / \mathrm{tahun}$.

Penerimaan dodol nanas dan dodol nanas crispy tahun 2017 sebesar Rp 480.000.000 juta. Dengan harga jual perkotak dodol nanas dan dodol nanas crispy sebesar Rp 10.000. (penerimaan dodol nanas 19.200x10.000 $=\mathrm{Rp} 192.000 .000$ juta/tahun dan dodol nanas crispy $28.800 \times 10.000=$ Rp 288.000.000 juta/tahun, total penerimaan dodol nanas dan dodol nanas crispy sebesar Rp192.000.000 + Rp288.000.000 = Rp480.000.000 juta/tahun.

Total biaya produksi sebesar Rp306.922.320 juta/tahun, biaya produksi dodol nanas yaitu biaya tetap (biaya penyusutan) + biaya variabel (biaya bahan baku+biaya bahan penunjang) $=\mathrm{Rp} 25043+\mathrm{Rp} 1.289 .500=\mathrm{Rp} 1.314 .543$ juta/hari, Rp1.314.543x8=Rp10.516.344 juta/bulan dan 10.516.344x12=Rp126.196.128 juta/tahun, sedangkan biaya dodol nanas crispy menghabiskan biaya sebesar, Rp25043+Rp1.230.000= Rp 1.255.043 juta/hari, Rp 1.255.043x12 = Rp15.060.516 juta/bulan dan Rp15.060.516 x12 = Rp180.726.192 juta/tahun. Total biaya produksi dodol nanas dan dodol nanas crispy yaitu Rp126.196.128 + 180.726.192 $=306.922 .320$ juta/tahun.

Keuntungan yaitu penerimaan - biaya produksi, keuntungan dodol nanas Rp192.000.000 - Rp 126.196.128 = Rp 65.803.872 juta/tahun sedangkan keuntungan dodol nanas crispy $\operatorname{Rp288.000.000~-~} \operatorname{Rp} 180.726 .192=$ Rp107.273.808 juta/tahun, jadi total keuntungan dodol nanas dan dodol nanas crispy sebesar Rp65.803.872 + Rp 107.273.808 = Rp 173.077.680juta/tahun

Dapat dihitung dengan menggunakan R/C Rasio, yaitu dengan membandingkan antara besarnya penerimaan dengan biaya yang dikeluarkan untuk produksi.

$$
\mathrm{R} / \mathrm{C}=\frac{480.000 .000}{306.922 .320}=1,57
$$

Hasil dari Penerimaan / Biaya produksi adalah 1,58 yang berarti bahwa usaha yang dijalankan sudah efisien sesuai dengan ketentuan efisiensi usaha yang mengatakan bahwa apabila $\mathrm{R} / \mathrm{C}>1$, maka usaha UKM dodol nanas Tulimario Yang dijalankan sudah efisien.

1,57>1, berarti usaha UKM dodol nanas Tulimario yang dijalankan sudah efisien.

\section{Prospek Pengembangan UKM Dodol Nanas di Tangkit Baru}

Prospek adalah suatu gambaran keseluruhan, baik ancaman ataupun peluang dari kegiatan pemasaran yang akan datang yang berhubungan dengan ketidak pastian dari aktifitas pemasaran atau penjualan. Dengan demikian prospek merupakan kondisi yang akan dihadapi oleh perusahaan dimasa yang akan datang baik kecendrungan untuk meningkatkan atau menutup.

Berdasarkan hasil wawancara kepada bagian keuangan UKM Tulimario tentang harapan prospek perkembangan UKM dodol nanas tersebut, dia berharap UKM Tulimario kedepannya makin maju dan dodol nanas makin banyak dikenal orang sebagai oleh-oleh khas jambi. Sedangkan harapan dari pegawainya sendiri tentang UKM dodol nanas Tulimario tersebut yaitu tetap berkembang dan dikenal banyak orang agar mereka mendapatkan biaya tambahan dari bekerja di UKM tersebut 
Faktor Internal Dalam Prospek Pengembangan Pengelolahan Dodol Nanas di Kabupaten Muaro Jambi

1. Kekuatan

a. Lokasi di daerah bahan baku industri pengelolaan dodol nanas Tulimario terletak di di Desa yang merupakan penghasil nanas terbesar di Kabupaten Muaro Jambi

b. Tenaga kerja mudah di dapat di daerah penelitian banyak tersedia tenaga kerja karena didaerah tersebut banyak penduduk yang tidak bekerja

c. Pangsa pasar luas untuk daerah Jambi pasar dari dodol nanas ini masih sangat luas. Ini disebabkan dodol nanas tersebut sudah dipasarkan ke beberapa pusat perbelanjaan di Jambi dan Riau.

d. Kelemahan

1. Sumber daya masyarakat (SDM) belum terlatih betul

2. Varian produk yang masih sedikit dibandingkan produk pesaing.

Faktor Eksternal Dalam Prospek Pengembangan Pengelolahan Dodol Nanas di Kabupaten Muaro Jambi

1. Peluang

a. Budaya masyarakat

Kebiasaan masyarakat membeli oleh-oleh dalam setiap bepergian sangat menunjang kemajuan industri pengelolahan dodol nanas Tulimario

b. Membuat varian baru

Membuat kue nastar, strategi ini dipilih karena sebentar lagi akan masuk bulan puasa dan Idul Fitri dimana kue nastar adalah cemilan yang cocok untuk di jual di bulan Ramadhan.

2. Ancaman

a. Munculnya pesaing baru

Kemungkinan munculnya industri serupa adalah sangat besar mengingat prospek industri pengelolaan dodol nanas cukup baik. Kemungkinan ini bisa terjadi karena ada beberapa karyawan yang keluar dari industri sehingga ada kemungkinan karyawan tersebut untuk melakukan usaha yang sama

b. Banyaknya produk lain

Banyak nya produk makanan modern sehingga UKM harus terus mengembangkan produknya.

Strategi Perkembangan Dodol Nanas Tulimario

1. Memperluas tempat penjualan, seperti menjual di tempat yang sering dikunjungi wisatawan seperti Candi Muaro Jambi, Gentala Arasyi, dan Jambi paradise. Agar lebih banyak yang mengenali produk buatan Desa Tangkit Baru ini.

2. Membuat varian baru yaitu dodol nanas crispy, strategi ini dipilih karena selain bentuknya yang unik dodol nanas crispy ini juga mempunyai rasa gurih yang di dapat dari kulit tepung dodol nanas crispy. 


\section{Penutup}

Pertama ketersediaan bahan penunjang yaitu tepung terigu dan gula pasir yang diperlukan untuk menjalankan industri pengelolaan dodol nanas tercukupi. Kedua diperoleh keuntungan yang diterima Rp173.077.680/thn. Industri pengelolaan dodol nanas di daerah penelitian ini menguntungkan karena dari hasi perhutungan diperoleh nilai TR adalah $\mathrm{Rp} 480.000 .000 /$ thn dan nilai TC adalah Rp306.922.320/thn (TR>TC) Efisiensi usaha yang cukup baik, karena dari hasil perhitungan diperoleh nilai $\mathrm{R}$ adalah $\mathrm{Rp} 480.000 .000 /$ thn dan nilai $\mathrm{C}$ adalah $\mathrm{Rp}$ Rp306.922.320 (R/C) = 1,57. 1,57>1, berarti usaha UKM dodol nanas Tulimario yang dijalankan sudah efisien. Ketiga strategi pengembangan industri pengelolahan dodol nanas yaitu dengan meningkatkan varian dodol nanas dan meningkatkan penjualan untuk memperbesar keuntungan dengan cara meningkatkan akses ke pasar yang lebih luas.

\section{BIBLIOGRAFI}

Satuhu, Suyanti dan Sunarmami. Membuat Aneka Dodol Buah , 2010.

Tresnawati, Dina. Analisis Pengembangan Agro industri Dodol Nanas di Kabupaten Subang. Surakarta: Skripsi, 2010.

Muhammad, Suwarsono. Manajemen Strategi Konsep dan Alat Analisis, Yogyakarta: Unit Penerbit dan Percetakan Sekolah Tinggi Ilmu Manajemen YKPN. 2013.

M. Syafi'ie El-Bantanie, Zakat Infak dan Sedekah, Bandung: Salamadani Pustaka Semesta, 2009.

Rozalinda. Ekonomi Islam Teori dan Aplikasinya pada Aktivitas Ekonomi, Jakarta: Rajawali Pers, 2014.

Sugioyo, Metode Penelitian Kuantitatif, Kualitatif, dan R\&D, Bandung: ALFABETA. 2016. 